\title{
SOSIALISASI PEMBUATAN PERMEN JELI KOPI SEBAGAI DIVERSIFIKASI PRODUK OLAHAN KOPI DI DESA PAKIS KECAMATAN PANTI JEMBER
}

\author{
SOCIALIZATION OF MAKING COFFEE JELLY CANDY AS \\ DIVERSIFICATION OF COFFEE PROCESSED PRODUCTS IN VILLAGE \\ PAKIS KECAMATAN PANTI JEMBER
}

\author{
Septy Handayani ${ }^{\# 1}$, Aji Sukoco ${ }^{\# 2}$ \\ \#Jurusan Teknologi Hasil Pertanian Universitas Jember \\ Jalan Kalimantan No. 37 Jember \\ shepty09@gmail.com
}

\begin{abstract}
Abstrak
Kegiatan Pengabdian Masyarakat Program Pengabdian Pemula (PPP) ini bertujuan untuk memberikan pelatihan kepada ibu-ibu anggota koperasi di Desa Pakis Kecamatan Panti Kabupaten Jember tentang pembuatan permen jeli sebagai diversifikasi produk olahan kopi, cara pengemasan, analisis usaha, serta pemasaran produk. Pelatihan ini perlu dilakukan karena proses produksi yang melimpah tidak diimbangi dengan penjualan yang terjadi di Desa Pakis, khususnya pada sektor kopi. Akibatnya, banyak petani yang rela merugi karena terpaksa menjual hasil panennya dengan harga yang murah, bahkan sering dibuang atau dikonsumsi pribadi. Oleh karena itu, diperlukan pembinaan terhadap petani dan masyarakat desa tersebut untuk mengolah kopi menjadi produk olahan yang siap konsumsi. Program pengabdian masyarakat ini diadakan untuk mengatasi masalah tersebut, bahkan diharapkan mampu meningkatkan kesejahteraan sosial masyarakat Desa Pakis. Kegiatan pengabdian masyarakat dilaksanakan selama 3 bulan, yaitu mulai bulan Oktober 2018 sampai Desember 2018. Jumlah peserta sekitar 20 orang ibu-ibu anggota koperasi. Kegiatan ini meliputi sosialisasi dan pelatihan pembuatan permen jeli, pendampingan pembukuan sederhana, dan pemasaran produk. Pelatihan dilaksanakan dengan metode ceramah, diskusi, peragaan oleh tim pelaksana, dan praktik dari para peserta pelatihan. Hasil kegiatan pengabdian ini menunjukkan respon seluruh peserta yang sangat antusias dalam mengikuti kegiatan serta adanya motivasi untuk mengembangkan permen jeli kopi menjadi bentuk usaha kecil.
\end{abstract}

Kata Kunci — Diversifikasi, kopi, permen jeli

\section{Abstract}

Community Service Activities Program Pengabdian Pemula (PPP) aims to provide training to women cooperative members in Pakis Village, Panti District, Jember Regency on making jelly candies as a diversification of coffee processed products, packaging methods, business analysis, and product marketing. This training needs to be done because the abundant production process is not matched by sales that occur in Desa Pakis, especially in the coffee sector. As a result, many farmers are willing to lose money because they are forced to sell their crops at low prices, often even discarded or consumed for personal consumption. Therefore, coaching is needed for farmers and villagers to process coffee into processed products that are ready for consumption. This community service program was held to overcome this problem, and even expected to be able to improve the social welfare of the people of Desa Pakis. Community service activities carried out for 3 months, from October 2018 to December 2018. The number of participants was around 20 mothers who were members of the cooperative. These activities include socialization and training in making jelly candy, simple bookkeeping assistance, and product marketing. The training was conducted using the lecture, discussion, demonstration methods by the implementation team, and the practice of the trainees. The results of this community service activity showed the response of all participants who were very enthusiastic in participating in the activity as well as the motivation to develop coffee jelly candy into a small business.

Keywords - Diversification, coffee, jelly candy

\section{PENDAHULUAN}

Kecamatan Panti merupakan salah satu dari 31 kecamatan di Kabupaten Jember dengan luasan wilayah mencapai $16071 \mathrm{~km} 2$ atau $4,88 \%$ dari luas wilayah keseluruhan Kabupaten Jember. Dengan ketinggian rata-rata 50-1340 mdpl. Kontur tanah yang beragam di Kecamatan Panti memungkinkan untuk dibudidayakan berbagai macam tanaman termasuk tanaman perkebunan (Abimanyu et al., 2018). Tanaman perkebunan yang banyak dibudidayakan adalah kopi. Kopi yang dibudidayakan di desa ini adalah kopi robusta.

Berdasarkan observasi yang dilakukan rata-rata kopi yang diproduksi hanya sampai kopi bubuk saja dan hasil panen tersebut belum banyak memberikan kontribusi dalam meningkatkan taraf hidup dan kesejahteraan masyarakat. Di Desa Pakis ini ada 
sebuah koperasi bernama "Koperasi Ketajek Makmur Jember" yang memproduksi kopi robusta menjadi kopi bubuk. Produksi kopi bubuknya cukup baik, tetapi saat musim panen kopi melimpah, permintaan kopi bubuk dari jenis tanpa grade sedikit sehingga sering kali tidak terjual.

Oleh karena itu, diperlukan diversifikasi produk olahan kopi untuk meningkatkan nilai ekonomi kopi dan pemanfaatan kopi menjadi produk pangan yang siap konsumsi. Salah satu produk pangan yang mudah pembuatannya dan siap konsumsi yaitu permen jeli kopi. Permen jeli memiliki tekstur lunak yang diproses dengan penambahan komponen hidrokoloid seperti agar-agar, gum, pektin, karagenan, dan gelatin sehingga menghasilkan produk yang kenyal (Suryani, 2004). Adapun tujuan dari pengabdian ini adalah untuk memberikan pengetahuan dan teknologi pengolahan permen jeli kopi, dan memberikan pengetahuan tentang proses pengemasan produk yang baik. Manfaat dari pengabdian ini diharapkan dapat meningkatkan kualitas sumber daya manusia dan meningkatkan kesejahteraan masyarakat di desa tersebut.

\section{TARGET DAN LUARAN}

Target luaran dari kegiatan pengabdian kepada masyarakat ini sebagai berikut:

a. Pembinaan dan pendampingan unit usaha pengolahan kopi menjadi produk permen jeli kopi dengan penambahan rasa jahe dan kayu manis melalui pendampingan pembukuan sederhana dan pemasaran produk.

b. Membantu pengadaan alat pendingin (kulkas), alat cetakan untuk cetak produk permen jeli, dan vacuum sealler. Rencana capaian tahunan dan indikator capaian dalam kegiatan pengabdian kepada masyarakat ini dapat dirinci pada Tabel 1

Selain itu, adanya teknologi yang diperkenalkan oleh pengusul adalah sebagai berikut:

1. Penggunaan bahan tambahan pangan yang aman dan dapat berperan sebagai pengawet produk.

2. Penggunaan kemasan yang sesuai untuk menjaga keamanan, masa simpan, dan daya tarik produk.

3. Penggunaan beberapa alat pengolahan tepat guna seperti vacuum sealler, timbangan digital, kulkas, dan alat cetakan.

4. Produk permen jeli yang diproduksi dengan tambahan rasa jahe dan kayu manis. Bahan yang diperlukan disajikan pada Tabel 2 .
TABEL I

JENIS LUARAN DAN CAPAIAN KEGIATAN

\begin{tabular}{|c|c|c|}
\hline $\mathbf{N}$ & Jenis Luaran & Indikator Capaian \\
\hline 1. & $\begin{array}{l}\text { Metode pembuatan } \\
\text { permen jeli kopi } \\
\text { dengan tambahan rasa } \\
\text { jahe dan kayu manis }\end{array}$ & Teknologi pengolahan \\
\hline 2. & $\begin{array}{lr}\text { Peningkatan } & \\
\text { Keterampilan } & \text { SDM } \\
\text { masyarakat } & \text { dalam } \\
\text { pengolahan } & \text { kopi, } \\
\text { pembukuan } & \text { sederhana } \\
\text { dan pemasaran produk }\end{array}$ & $\begin{array}{l}\text { SDM terampil dalam } \\
\text { produksi, pembukuan } \\
\text { dan pemasaran }\end{array}$ \\
\hline 3. & $\begin{array}{l}\text { Diversifikasi kopi } \\
\text { menjadi produk olahan } \\
\text { yang siap konsumsi } \\
\text { sehingga meningkatkan } \\
\text { daya jual kopi dan } \\
\text { produk olahan kopi }\end{array}$ & $\begin{array}{l}\text { Daya jual } r \\
\text { meningkat } \\
\text { produk awal dari biji } \\
\text { kopi menjadi permen } \\
\text { jeli }\end{array}$ \\
\hline 4. & $\begin{array}{l}\text { Publikasi Ilmiah pada } \\
\text { Warta Pengabdian / } \\
\text { Media Massa }\end{array}$ & $\begin{array}{l}\text { Warta Pengabdian LPM } \\
\text { UNEJ atau Radar } \\
\text { Jember }\end{array}$ \\
\hline
\end{tabular}

TABEL III

Bahan yang DIbutuhKan Pada PEMbuatan PERmen Jeli

\begin{tabular}{|c|c|}
\hline Bahan & Jumlah \\
\hline Seduhan Kopi (ml) & 25 \\
\hline Karagenan (g) & 10 \\
\hline Sirup glukosa (g) & 10 \\
\hline Sukrosa (g) & 38 \\
\hline Asam sitrat (g) & 0,5 \\
\hline Jahe / kayu manis (g) & 0,5 \\
\hline Air (ml) & 100 \\
\hline
\end{tabular}

\section{METODE PELAKSANAAN}

Kegiatan pengabdian masyarakat ini dilaksanakan dengan metode ceramah, diskusi, peragaan langsung oleh tim pelaksana pengabdian masyarakat, dan praktik langsung dari para peserta pelatihan.

\section{A. Ceramah}

Metode ini dilaksanakan dengan memberikan materi secara lisan yang didukung oleh alat dan media penyampaian materi. Peserta pelatihan juga akan diberi modul untuk mempermudah dalam mengikuti penyampaian materi oleh tim pelaksana pengabdian masyarakat. Materi yang akan disampaikan meliputi materi mengenai proses pembuatan permen jeli dengan tambahan rasa alami dan cara pengemasan yang menarik. Materi kedua adalah memberikan penjelasan mengenai estimasi analisis usaha permen jeli.

B. Diskusi

Peserta dipersilakan untuk menyampaikan pernyataan atau pertanyaan yang bersifat problematik dan akan dipecahkan bersama. 
Pertanyaan tidak hanya dijawab oleh tim pelaksana pengabdian masyarakat, peserta lain juga dapat berperan aktif dalam menjawab pertanyaan sebagai tambahan informasi dalam rangka memecahkan permasalahan yang ditinjau dari berbagai aspek yang masih berkaitan dengan materi.

C. Peragaan oleh Tim Pelaksana Pengabdian Masyarakat

Peragaan pembuatan permen jeli akan dilakukan oleh tim pelaksana pengabdian masyarakat sehingga para peserta dapat melihat, memperhatikan, dan nantinya mempraktikkan langkah-langkah pembuatannya. Peserta akan ditunjukkan cara pembuatan permen jeli dan akan disediakan contoh produk permen jeli.

D. Praktik Langsung oleh Peserta Pelatihan

Praktik langsung oleh peserta dilakukan secara berkelompok. Masing-masing kelompok akan disediakan bahan-bahan yang dibutuhkan untuk pembuatan produk permen jeli. Selain itu, pada pelaksanaan praktik ini juga dilakukan pendampingan oleh tim pelaksana pengabdian masyarakat. Secara garis besar metode pelaksanaan kegiatan pengabdian masyarakat selama 3 (tiga) bulan, dapat dilihat pada Tabel 3.

Peserta pelatihan adalah ibu-ibu anggota koperasi Desa Pakis Kecamatan Panti yang dalam hal ini berperan sebagai mitra. Peserta pelatihan dibuat menjadi beberapa kelompok, dalam 1 kelompok terdiri atas 4 orang. Setiap kelompok ditugaskan untuk membawa 4 sendok, 3 panci kecil, 1 kompor, dan 5 wadah kecil sehingga proses pelatihan dapat berjalan lancar. Alat lain seperti timbangan dan kulkas akan disediakan oleh tim pelaksana pengabdian masyarakat atas bantuan anggota koperasi. Selain itu, nantinya peserta juga akan diberikan formulir evaluasi sensori untuk menguji setiap permen jeli yang telah dibuat masingmasing kelompok. Setelah data dikumpulkan dan dianalisis maka dapat ditentukan permen jeli dengan sifat sensori terbaik.

Proses pembuatan permen jeli diawali dengan membuat ekstrak kopi terlebih dahulu atau biasa disebut dengan membuat seduhan kopi. Kopi bubuk dan air mendidih menggunakan perbandingan 1:5 (kopi:air = 1:5). Kopi bubuk yang digunakan yaitu kopi bubuk yang diproduksi sendiri oleh Koperasi Ketajek Makmur Jember. Kemudian kopi yang telah diberi air panas tersebut diseduh atau didiamkan selama \pm 5 menit dan diambil air seduhan bagian atas sebanyak $25 \mathrm{ml}$. Setelah itu, ditambahkan karagenan atau alginat sebagai pembentuk gel dalam permen jeli sebanyak $10 \mathrm{~g}$, sirup glukosa sebanyak $10 \mathrm{~g}$, sukrosa sebanyak $38 \mathrm{~g}$, asam sitrat sebanyak $0,5 \mathrm{~g}$, dan penambahan air matang sebanyak $100 \mathrm{ml}$. Selanjutnya dilakukan pemanasan sampai mendidih sambil diaduk. Setelah mendidih adonan permen jeli dituangkan ke dalam cetakan yang selanjutnya didiamkan selama 1 jam di suhu ruang. Setelah itu, dimasukkan ke lemari pendingin selama \pm 12 jam.

TABEL IIIII

PELAKSANAAN KEGIATAN PENGABDIAN MASYARAKAT

\begin{tabular}{|c|c|c|c|c|}
\hline No & $\begin{array}{c}\text { Jenis } \\
\text { Kegiatan }\end{array}$ & Sasaran & $\begin{array}{c}\text { Bentuk } \\
\text { Kegiatan }\end{array}$ & Pendukung \\
\hline 1. & $\begin{array}{l}\text { Sosialisasi } \\
\text { dan } \\
\text { pelatihan } \\
\text { permen } \\
\text { jeli kopi } \\
\text { dengan } \\
\text { penambah } \\
\text { an rasa } \\
\text { (jahe dan } \\
\text { kayu } \\
\text { manis) }\end{array}$ & $\begin{array}{l}\text { Masyarak } \\
\text { at } \\
\text { khususny } \\
\text { a ibu-ibu } \\
\text { anggota } \\
\text { koperasi }\end{array}$ & 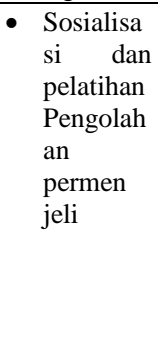 & $\begin{array}{l}\text { Ketua dan } \\
\text { Anggota } \\
\text { pelaksana, } \\
\text { Dua } \\
\text { mahasiswa } \\
\text { FTP } \\
\text { UNEJ, } \\
\text { Anggota } \\
\text { koperasi }\end{array}$ \\
\hline 2. & $\begin{array}{l}\text { Pengadaan } \\
\text { peralatan } \\
\text { sederhana }\end{array}$ & $\begin{array}{l}\text { Kelompo } \\
\mathrm{k} \text { ibu-ibu } \\
\text { anggota } \\
\text { koperasi }\end{array}$ & $\begin{array}{l}\text { - Penyerah } \\
\text { an alat } \\
\text { berupa } \\
\text { kulkas, } \\
\text { alat } \\
\text { cetakan, } \\
\text { dan } \\
\text { vacuum } \\
\text { sealler }\end{array}$ & $\begin{array}{l}\text { Ketua dan } \\
\text { Anggota } \\
\text { pelaksana }\end{array}$ \\
\hline 3. & $\begin{array}{l}\text { Pendampi } \\
\text { ngan } \\
\text { Pembukua } \\
\text { n } \\
\text { sederhana, } \\
\text { dan } \\
\text { pemasaran } \\
\text { produk }\end{array}$ & $\begin{array}{l}\text { Kelompo } \\
\mathrm{k} \text { ibu-ibu } \\
\text { anggota } \\
\text { koperasi }\end{array}$ & $\begin{array}{l}\text { - Pendamp } \\
\text { ingan }\end{array}$ & $\begin{array}{l}\text { Ketua dan } \\
\text { Anggota } \\
\text { Pelaksana }\end{array}$ \\
\hline
\end{tabular}

\section{HASIL DAN PEMBAHASAN}

\section{A. Persiapan Pelaksanaan Sosialisasi}

Persiapan pelaksanaan sosialisasi dilakukan untuk mempersiapkan segala kebutuhan pada saat pelaksanaan sehingga kegiatan dapat berlangsung dengan lancar dan tujuan kegiatan dapat tercapai. Pada persiapan ini tim pelaksana kegiatan sosialisasi melakukan beberapa persiapan yaitu persiapan alat dan bahan sebagai penunjang kegiatan, persiapan pembuatan produk permen jeli kopi yang akan disosialisasikan, dan persiapan tempat serta peserta kegiatan dalam hal ini Koperasi Ketajek Makmur Jember yang beralamat di Desa Pakis Kecamatan Panti Kabupaten Jember. Bangunan Koperasi Ketajek Makmur di Desa Pakis Kecamatan Panti Jember dapat dilihat pada Gambar 1. 


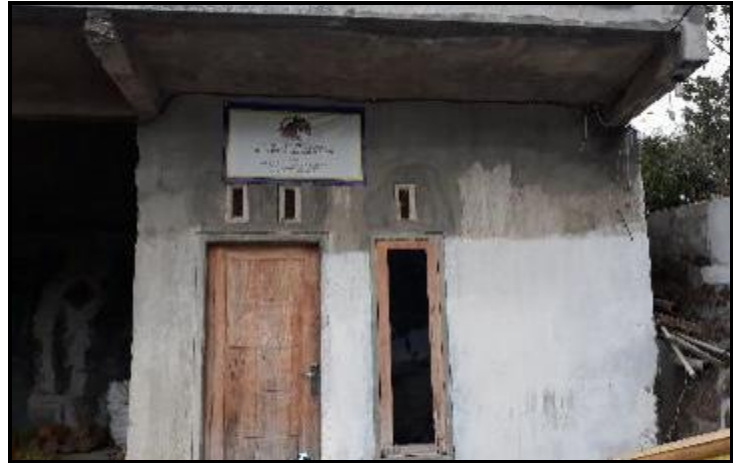

Gambar 1. Bangunan Koperasi Ketajek Makmur di Desa Pakis Kecamatan Panti Jember

Persiapan alat dan bahan sebagai penunjang kegiatan dilakukan sejak bulan Oktober sampai November 2018. Kegiatan dilakukan dengan pembelian dan persiapan alat serta bahan penunjang. Selain itu, beberapa kali dilakukan kunjungan ke koperasi sebagai tempat pelaksanaan kegiatan guna memastikan alat penunjang yang dibutuhkan saat pelaksanaan siap digunakan dan tersedia. Kebutuhan persediaan alat penunjang kegiatan diserahkan kepada penanggung jawab koperasi yaitu Ibu Sumiati serta Pak Wardoyo selaku ketua koperasi Ketajek Makmur Jember.

Persiapan selanjutnya yaitu pembuatan produk permen jeli yang dilakukan oleh tim pelaksana kegiatan sosialisasi ini. Tim pelaksana melakukan studi pustaka untuk mendapatkan formulasi yang tepat dan sesuai. Selain itu, pertimbangan lain mengenai ketersediaan bahan juga masuk dalam persiapan tim pelaksana agar keberlanjutan pembuatan produk permen jeli ini dapat terlaksana dan menjadi salah satu produk unggulan koperasi di Desa Pakis ini. Tempat pelaksanaan kegiatan juga dipersiapkan dengan sebaik mungkin oleh tim pelaksana. Hal ini bertujuan untuk kelancaran kegiatan sosialisasi. Pelaksanaan kegiatan akan dilakukan di halaman kantor Koperasi Ketajek Makmur Jember.

\section{B. Pembuatan Produk Permen Jeli Kopi}

Pembuatan permen jeli kopi ini pada awalnya dilakukan sesuai dengan pustaka tentang pembuatan permen jeli, tetapi pada pelaksanaannya ditemukan berbagai kendala seperti tekstur permen jeli yang tidak sesuai dengan standar dan rasa kopi yang kurang dominan. Oleh karena itu, tim pelaksana membuat formulasi kembali dengan memodifikasi formula yang sudah ada tersebut. Formulasi ini dilakukan pergantian sampai $3 \mathrm{kali}$ untuk mendapatkan permen jeli kopi yang sesuai. Kopi dan bubuk kopi Koperasi Ketajek Makmur Jember dapat dilihat pada Gambar 2.

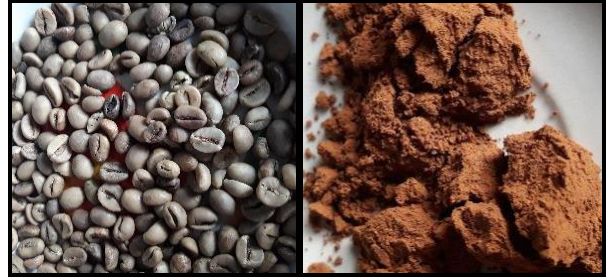

(a)

(b)

Gambar 2. Kopi dan Bubuk Kopi Koperasi Ketajek Makmur Jember

Proses pembuatan permen jeli diawali dengan membuat ekstrak kopi terlebih dahulu atau biasa disebut dengan membuat seduhan kopi. Pembuatan permen jeli kopi disesuaikan dengan metode awal yang sudah ditetapkan yaitu pembuatan seduhan kopi sebagai ekstrak kopi yang akan dicampur pada adonan permen jeli. Kemudian pembuatan permen jeli kopi. Berdasarkan hal tersebut, kopi bubuk dan air mendidih yang sesuai dengan menggunakan perbandingan 1:5 (kopi:air = 1:5). Kopi bubuk yang digunakan yaitu kopi bubuk yang diproduksi sendiri oleh Koperasi Ketajek Makmur Jember. Setelah itu, pembuatan permen jeli sesuai dengan metode pelaksanaan yang sudah ada dengan formulasi yang tepat dan sesuai.

\section{Sosialisasi Pembuatan Permen Jeli Kopi}

Sosialisasi pembuatan permen jeli kopi dilaksanakan pada Hari Sabtu tanggal 24 November 2018 dengan judul kegiatan sosialisasi pembuatan permen jeli kopi di Desa Pakis Kecamatan Panti Kabupaten Jember. Kegiatan dilaksanakan di halaman kantor Koperasi Ketajek Makmur Jember dengan peserta 20 orang ibu-ibu anggota koperasi.

Pelaksanaan sosialisasi terlaksana dengan baik dengan antusias ibu-ibu anggota koperasi sebagai peserta. Peserta dibagi menjadi 4 kelompok dengan masing-masing terdiri dari 5 orang. Pelaksanaan dilakukan dengan ceramah atau pemberian materi mengenai latar belakang hingga proses pembuatan permen jeli kopi serta penjelasan sederhana mengenai pembukuan dan penjualan produk.

Praktik pembuatan permen jeli kopi dilakukan setelah materi disampaikan. Ibu-ibu sangat antusias dalam praktik membuat permen jeli kopi, sehingga dapat membuat permen jeli kopi dengan baik. Hanya saja ada kendala saat penuangan ke cetakan beberapa kelompok kurang berhasil menuangkan dikarenakan adonan permen jeli kopi sudah agak dingin. Namun, secara keseluruhan ibu-ibu dapat membuat permen jeli kopi dengan baik dan sangat antusias. Selain itu, ibu Sumiati selaku ketua bersama ibu Siti juga antusias mengembangkan pelatihan ini tidak hanya sekedar pelatihan tetapi sebagai bentuk usaha di koperasi tersebut. Suasana kegiatan sosialisasi pembuatan permen jeli kopi dapat dilihat pada 
Gambar 3 dan permen jeli kopi dapat dilihat pada Gambar 4.

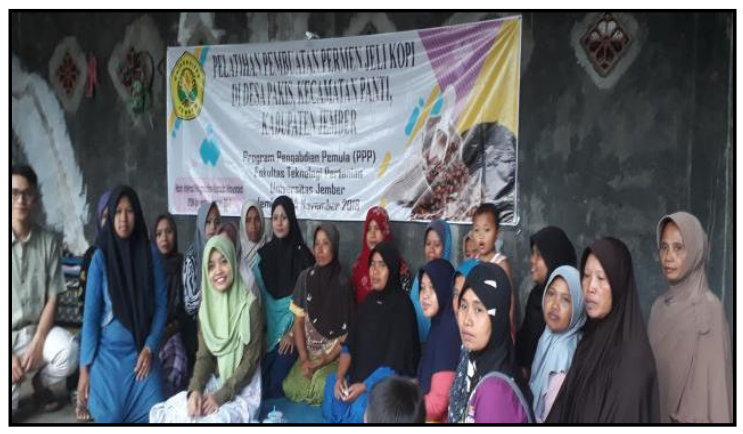

Gambar 3. Suasana Kegiatan Sosialisasi Pembuatan Permen Jeli Kopi

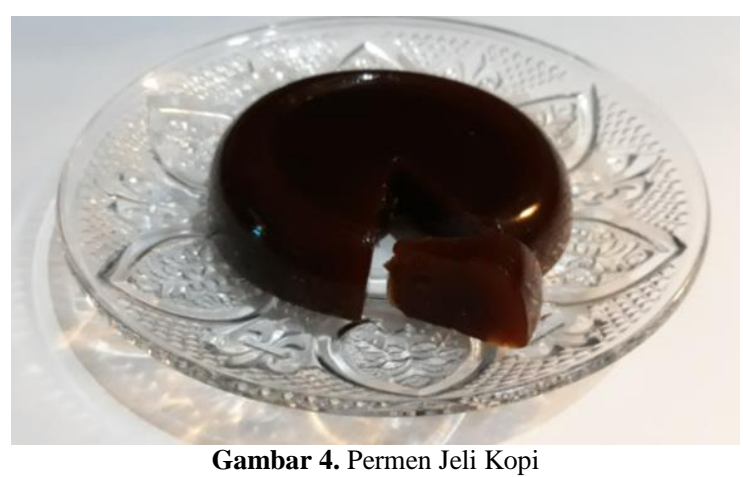

\section{KESIMPULAN}

Persiapan pelaksanaan kegiatan sosialisasi sangat diperlukan agar saat pelaksanaannya dapat berjalan dengan lancar dan sesuai dengan prosedur. Selain itu, ketersediaan alat dan bahan sebagai penunjang dalam kegiatan tersebut dapat direalisasikan dengan baik. Namun, pelaksanaan kegiatan ini menjadi cukup panjang dikarenakan tim pelaksana juga melakukan proses pembuatan produk permen jeli kopi yang mengalami kendala pada formulasi awal. Oleh karena itu, pelaksanaan kegiatan sosialisasi pembuatan permen jeli kopi kepada ibu-ibu anggota Koperasi Ketajek Makmur Jember dilakukan pada tanggal 24 November 2018. Pelaksanaan pelatihan pada tanggal tersebut diikuti oleh ibu-ibu yang sangat antusias sehingga pelaksanaannya menjadi lancar dan baik serta dapat menimbulkan kreativitas ibu-ibu yang ingin usaha permen jeli kopi.

\section{UCAPAN TERIMA KASIH}

Ucapan terima kasih yang sebesar-besarnya ditujukan atas bantuan, dukungan, dan kerjasama dari berbagai pihak yang terkait. Pihak yang terkait dalam kegiatan ini adalah pihak pemberi dana Hibah Internal Lembaga Penelitian dan Pengabdian Masyarakat Universitas Jember tahun 2018 serta pihak Koperasi Ketajek Makmur Jember yang menjadi tempat kegiatan.

\section{DAFTAR PUSTAKA}

[1] Abimanyu, W., Hadi, S., dan Ridho, A.A. 2018. Studi Komparatif Usaha Perkebunan Kopi Robusta dan Kopi Arabika di Kecamatan Panti Kabupaten Jember. Jurnal Agribest, 2 (1), pp. 14-23.

[2] Hidayat, N., dan Ken, L. 2004. Membuat Permen Jeli. Trubus Agrisarana, Surabaya.

[3] Herlina, L. 2014."Kajian Konsentrasi Maltodekstrin dan Polivinil Pirolidon (PVP) Pada Tablet Effervescent Kopi Robusta (Coffea robusta Lindl)". Thesis. Universitas Pasundan, Bandung.

[4] Pangestika, D., Mirani, E., dan Mashoedi, I.D. 2012. Pengaruh Pemberian Kunyit Curcuma domestica Val.) terhadap Aktivitas Fagositosis Makrofag pada Mencit BALB/C yang Diinokulasi Bakteri Lysteria monocytogenes. Journal Sains Medika, 4 (1), pp. 6370.

[5] Rismunandar dan Paimin, F.B. 2001. Kayu Manis Budidaya dan Pengolahan. Penebar Swadaya, Jakarta.

[6] Suryani, L. 2004. Membuat Aneka Buah. Kanisius, Yogyakarta. 